\title{
Kernos
}

Revue internationale et pluridisciplinaire de religion grecque antique

15 | 2002

Varia

\section{Pierre BRULÉ, Les femmes grecques à l'époque classique}

\author{
Vinciane Pirenne-Delforge
}

URL : http://journals.openedition.org/kernos/1433

DOI : 10.4000/kernos.1433

ISSN : 2034-7871

\section{Éditeur}

Centre international d'étude de la religion grecque antique

\section{Édition imprimée}

Date de publication : 1 janvier 2002

ISSN : 0776-3824

\section{Référence électronique}

Vinciane Pirenne-Delforge, «Pierre BruLÉ, Les femmes grecques à l'époque classique », Kernos [En ligne], 15 | 2002, mis en ligne le 22 avril 2011, consulté le 24 septembre 2020. URL : http:// journals.openedition.org/kernos/1433; DOI : https://doi.org/10.4000/kernos.1433 
divinazione », p. 179-283). L'Agamemnon d'Eschyle, les Troyennes d'Euripide et l'Alexandra de Lycophron, ainsi que des textes hellénistiques mineurs sont étudiés. Ces ouvres ont en commun la présentation des prophéties de Cassandre soumise à la transe mantique et deviennent des documents capitaux non seulement pour établir un profil précis de la modalité de la mantique représentée par l'héroïne à un moment donné, mais aussi pour mieux comprendre les conceptions grecques sur le procès divinatoire 'inspiré' et les traits des messages verbalisés qui en dérivent. Ces sont donc des textes assez particuliers, et dans la forme et dans le contenu, et des documents très représentatifs de leurs périodes respectives du point de vue social et littéraire. L'A. a réussit a délimiter parfaitement les traits complexes de la Cassandre d'Eschyle et de sa transe. Cette complexité est due à la variété de moments qui constituent la 'performance' de cette transe et de la différence d'intensité de chaque phase. La séquence sujet de cet analyse (vers 1072-1330, précédée d'un silence non moins expressif de Cassandre) est composée de quatre stades ( $c f$. le tableau de la p. 218): (A) des cris et invocation rituelle, (B) clairvoyance non médiate, (C) clairvoyance médiate et rationalité, et (D) prophétie rationnelle, intelligibilité. Chacun de ces stades peut être divisé en quatre phases en climax, d'extension variable. Cette analyse (présentée ici de façon trop résumée) est accompagnée d'une étude du langage qui caractérise la scène. En ce qui concerne les Troyennes, l'A. montre qu'il ne s'agit pas d'une transe, d'un 'invasamento del dio' (comme chez Eschyle), mais d'une modalité caractérisée, dans sa manifestation extérieure, par une mania définie explicitement ( $c f$. le lexique) comme bacchique et qui, par la modalité de son message, est plutôt un rapport qu'une prophétie en tant que telle. Cette 'folie' contribue à renforcer la marginalité du personnage et se trouve à la base du traitement de Cassandre dans la littérature européenne postérieure.

Je soulignerai enfin la finesse et la rigueur méthodologique du commentaire de l'Alexandra de Lycophron. Ce texte, profondément représentatif des traits de la littérature hllénistique, transforme la prophétie de Cassandre (moyennant une rupture entre elle et le destinataire, en ayant recours au gardian de la prison, qui en fait le rapport) en une énigme prolongée. "L'alvi $\gamma \mu \alpha$ è predilezione alessandrina nell'ambito del clima culturale e intellettuale in cui visse Licofrone: l'autore gli conferisce carattere normativo all'interno del monologo oracolare, piegando la profezia ai dettami della poetica vigente, e tramite l'uno legittima l'altra " (p. 259). On soulignera aussi l'utilité du tableau des p. 267-269, qui contient un schéma de l'Alexandra où les niveaux chronologiques du poème (temps présent, 'flashback', temps futur et prophétie sur un futur qui précède les événements du récit principal) sont typographiquement différenciés.

Il s'agit donc d'une importante contribution à la connaissance de la prophétie dans le Monde Ancien, à l'approfondissement de l'étude des figures mantiques du mythe et à l'analyse littéraire et linguistique des ouvres qui accueillent le personnage.

Emilio Suárez de la Torre (Universidad de Valladolid)

Pierre Brulé, Les femmes grecques à l'époque classique, Paris, Hachette Littératures, 2001. 1 vol. $14 \times 22 \mathrm{~cm}, 282$ p. (Coll. La vie quotidienne). ISBN : 2-01-235480-7.

Avec un tel interprète, la femme grecque ne pouvait rester muette, fade et recluse. En effet, après son imposante thèse sur La fille d'Athènes (Paris, 1987), P. Brulé était tout désigné pour dessiner ce portrait féminin, en laissant de côté ce que l'exercice de la thèse peut avoir de contraignant. Le propos est donc alerte, le 
style enlevé, la documentation très riche et les textes abondamment traduits (mais trop souvent sans références...). Il ne s'agit pas d'un $x^{\text {e }}$ livre sur les femmes grecques, venant après tant d'autres, compenser enfin le silence, long et obstiné, d'une certaine historiographie. Il s'agit d'un très beau livre, généreux, haut en couleurs, qui donne véritablement vie aux femmes grecques, à défaut d'avoir vraiment la possibilité de leur donner la parole puisque les intermédiaires de notre information sont presque toujours masculins. Il s'agit aussi d'un exercice de méthode historique, même si l'originalité du ton rompt délibérément avec le style habituel de la synthèse en histoire.

C'est du côté du religieux que s'ouvre le propos avec «Le féminin, les femmes et le sacré ». D'une interrogation sur le divin féminin en passant par les prêtrises et les rituels spécifiques (Déméter, Dionysos), il ressort que « la religion constitue un révélateur à la fois précis et puissant du féminin grec ». Puis l'on en vient aux portraits épiques, de Briséis et Chryséis à Pénélope en passant par Nausicaa, mais sans Hélène. L'étude des mots pour dire la femme, la fille, la fille de... est particulièrement éclairante. Le chapitre suivant traite « Du corps et du comportement ", passant ainsi de l'épopée à la biologie d'Aristote et des méde cins : polarité sexuelle, sexualité et fécondation sont autant de lieux où s'exprime une lecture masculine, idéologiquement marquée, du corps des femmes. Après le biologique, le social: un parcours dans l'oikos de Périclès ouvre à la compréhension des pratiques d'échange matrimonial entre grandes familles et à celle des questions d'âge au mariage, d'amours sexuellement différents, de filles et de garçons et, en intermezzo, de rites nuptiaux. Puis c'est l'expérience de l'Ischomaque de Xénophon face à sa toute jeune épouse qui est finement décrite, pour en arriver aux Aspasie et autres Nééra, les courtisanes de haut vol, hors du système de 1' « endogamie politique », La toute dernière partie s'intitule «Comment les quitter?": sur un poème de Sappho, bien sûr ! Une très brève bibliographie presque exclusivement francophone vient en fin d'ouvrage et s'achève par la mention de trois thèses patronnées par l'A. et non encore publiées. Un beau geste d'enseignant.

P. Brulé nous montre avec empathie qu'après une sorte de nécessité pour les femmes grecques de trouver des interprètes féminines dans le monde des historiens contemporains (les gender studies furent d'abord féministes, puis féminines), un porte-parole masculin leur rend aujourd'hui pleinement et joliment justice.

Vinciane Pirenne-Delforge (Université de Liège)

\section{Daniela CASTALdo, Il Pantheon Musicale. Iconografia nella ceramica attica} tra VI e IV secolo, Ravenna, Longo Editore, 2000. 1 vol. $17 \times 24 \mathrm{~cm}, 325$ p., 174 fig. ISBN : 88-8063-213-2.

Ce livre est la publication d'une thèse de doctorat, rédigée à l'Université de Lausanne sous la direction du professeur Claude Bérard. L'A. part du constat que les témoignages iconographiques sur la musique grecque antique offrent une image différente de celle que nous donnent les sources écrites. Cette divergence est encore plus nette, à son avis, dans la musique des dieux. Aussi rassemble-t-elle et présente-t-elle dans son livre les représentations de la musique du panthéon olympien dans la céramique attique du $\mathrm{vI}^{\mathrm{e}}$ au $\mathrm{Iv}^{\mathrm{e}}$ siècle av. J.-C. Elle organise son sujet autour des figures d'Apollon et de Dionysos en distinguant deux genres de musique, dont elle définit le caractère différent : la musique apollinienne, d'une part, et la musique associée à Dionysos et son entourage, de l'autre. Sa discussion comprend aussi d'autres divinités, dont les liens avec la musique sont moins 